\title{
Avaliação da retenção de sólidos em inovadora configuração de reator UASB tratando esgoto doméstico
}

\section{Solids retention in a new model of UASB reactor applied to domestic wastewater treatment}

Data de entrada: $15 / 03 / 2016$

- Data de aprovação: 01/04/2016

Jozielle Marques da Rocha, Gutemberg Geraldo Vilaça Faleiro, Jane Silva Ferreira Magalhães, Jackson de Oliveira Pereira

DOI:10.4322/dae.2016.021

\section{RESUMO}

A retenção de sólidos é um dos principais problemas de reatores UASB tratando esgoto doméstico. Apesar disso, estudos que proponham melhorar esse aspecto são escassos. Nesse sentido, o presente projeto avaliou o desempenho de uma configuração modificada de reator UASB com foco na redução da velocidade na passagem para o compartimento de decantação, que pode limitar o retorno do lodo ao fundo do reator. Para tanto, o reator foi projetado com duas passagens distintas, e seu desempenho foi comparado a um reator convencional. Os resultados indicaram a maior retenção de sólidos no reator modificado, que apresentou menores concentrações de SST no efluente (73-88 mg/L) comparado ao reator convencional (82-106 mg/L). Além disso, houve uma significativa maior produção de metano no reator modificado, devido ao maior tempo de permanência dos sólidos no reator (20-50\%). Assim, o reator apresentou um bom potencial de aplicação sob esse aspecto.

Palavras-chave: tratamento anaeróbio de esgoto, reator UASB, projeto do separador de fases, remoção de sólidos, retenção física de sólidos.

\section{ABSTRACT}

Solids retention is one of main problems of UASB reactors treating domestic sewage. Nevertheless, studies that propose to improve this aspect are scarce. In this sense, this project evaluated the performance of a modified UASB reactor with a focus on reducing the upflow velocity in the passage to the settling compartment, which can limit the sludge return to the reactor bottom. Thus, the reactor was designed with two distinct passages, and their performance was compared to a conventional reactor. The results indicated higher retention of solids in the modified reactor which showed the lowest concentrations in the TSS effluent (73-88 mg / L) compared to the conventional reactor (82-106 mg / L). Moreover, a significant higher production of methane in the modifiedreactor was observed due to higher solids residence time in the reactor (20-50\%). Thus, the reactor showed a good potential application in this purpose.

Keywords: anaerobic sewage treatment, UASB reactor, phase separator project, solids removal, solids physical retention.

Jozielle Marques da Rocha - Graduanda em Engenharia Civil pela Universidade Federal de São João del-Rei (UFSJ). Técnica em Edificações pelo Instituto Federal de Minas Gerais - (IFMG/OP). Bolsista de Iniciação Científica do CNPq. Endereço: Rua dos Amaros, nº 526 - Centro - Inhapim Minas Gerais/MG - CEP: 35330-000 - Brasil. Tel: +55(31) 993000637 - e-mail: joziellemrochaagmail.com.

Gutemberg Geraldo Vilaça Faleiro - Engenheiro Civil pela Universidade Federal de São João del-Rei (UFSJ). Engenheiro de drenagem de vias urbanas da Terrasa Engenharia LTDa. Endereço para correspondência: Rua Josefino de Morais, n 162 - Passa Tempo - Minas Gerais / MG - CEP: 35537-000 - Brasil. Tel: +55 (31) 99851-5226 - email: gutembergfaleiroaoutlook.com.

Jane Silva Ferreira Magalhães - Graduanda de Engenharia Química pela Universidade Federal de São João del-Rei (UFSJ). Endereço para correspondência: Rua Copacabana, n¹66 - Giovannini - Coronel Fabriciano - Minas Gerais/MG - CEP: 35170-098 - Brasil. Tel+55(31)98771724 e-mail: jane fmagalhaesahotmail.com.

Jackson de Oliveira Pereira - Engenheiro Civil pela UFV. Doutor em Saneamento, Meio Ambiente e Recursos Hídricos pela UFMG. Professor Adjunto III do Departamento de Tecnologia em Engenharia Civil, Computação e Humanidades da Universidade Federal de São João del-Rei (DTECH/UFSJ). Endereço para correspondência: DETCH/UFSJ - Campus Alto Paraopeba. Rodovia MG 443 - km 07 - Fazenda do Cadete - 36420000 - Ouro Branco MG - Tel: (031) 3741-3193 - Fax (031) 3238-1879 - E-mail: jacksonaufsj.edu.br. 


\section{INTRODUÇÃO}

O aperfeiçoamento tecnológico de reatores UASB para tratamento de esgoto doméstico constitui uma demanda premente dos prestadores de serviços, uma vez que a tecnologia demonstrou sérias limitações, especialmente no que se refere ao acúmulo de escuma no separador trifásico, à perda de gases para atmosfera e a geração de maus odores, e a perda excessiva de sólidos no efluente (CHERNICHARO et al., 2015).

Entre estas limitações apresentadas pela configuração do reator, pode-se dizer que o problema da retenção física dos sólidos é aquele que tem recebido menor atenção. Isso porque, usualmente, o problema acaba sendo minimizado com o controle rigoroso dos descartes de lodo e, quando isso não acontece, como os reatores incorporam uma etapa de pós-tratamento, a remoção desses sólidos acaba sendo delegada a essas unidades. Decorre que a presença de elevadas concentrações de sólidos no efluente dos reatores impede que os sistemas de pós-tratamento promovam a remoção biológica dos nutrientes, deixando de cumprir seu verdadeiro papel e passando a desempenhar apenas o polimento do efluente do reator (LEITÃO, 2004).

Basicamente, a retenção física de sólidos no reator pode ser atribuída à existência do compartimento de decantação, na porção superior do separador trifásico, onde os sólidos que foram arrastados do fundo do reator encontram boas condições para sedimentação. O lodo vai sendo depositado sobre a coifa e, devido à elevada inclinação desse elemento, desliza até a abertura de passagem do compartimento de digestão para o compartimento de decantação, para então retornar ao fundo do reator. Esse mecanismo confere ao reator a manutenção de uma elevada quantidade de biomassa, a independência do tempo de detenção hidráulica, e a produção de um efluente com baixos teores de sólidos suspensos (SANTOS et al., 2016). Entretanto, essa eficiência do decan- tador será reduzida quando do aumento das velocidades do esgoto em tratamento, e quando o reator encontra-se com sua massa máxima possível no compartimento de digestão, "reator cheio" (AIUKY et al., 2010; VAN HAANDEL et al., 2015). Como consequência dessas situações, haverá o comprometimento da eficiência do tratamento, em razão da perda excessiva de sólidos suspensos no efluente do reator.

Apesar das velocidades serem controladas no momento do projeto (ABNT/NBR 12209, 2011), usualmente, o reator está suscetível às variações horárias da vazão afluente, que proporcionam uma elevação momentânea destas velocidades. Além de reduzir a eficiência do decantador, essa elevação momentânea da velocidade ascensional ocasiona a expansão da manta de lodo, e o maior aporte de sólidos para essa região, que fatalmente serão descarregados com o efluente. Segundo Leitão (2004), esse efeito pode ser controlado mantendo-se a altura da manta de lodo entre $70 \mathrm{e}$ $80 \%$ da distância entre o fundo do reator e o separador de fases. Analogamente, poderia se pensar na elevação do separador trifásico, porém, para se manter a mesma altura total, isso só seria possível com a redução da inclinação do separador.

As partículas que atingirem o compartimento de decantação só terão a possibilidade de retornar ao fundo do reator se, primeiramente, possuírem velocidade de sedimentação superior à velocidade ascensional do esgoto. Como é bem provável que a maioria das partículas arrastadas pelo fluxo não possuam tal característica, isso só será alcançado se houver o contato e a agregação entre as mesmas, ao longo da profundidade do decantador, e a formação de flocos de sedimentabilidade superior à velocidade do fluxo. Do contrário, fatalmente, todas essas partículas sólidas serão descarregadas com o efluente (VAN HAANDEL et al., 2015). Após esse processo inicial, os pequenos flocos sedimentarão sobre a parede inclinada do separador e deslizarão na direção da abertu- 
ra de passagem. Entretanto, nessa região, devido ao estrangulamento na seção de escoamento, na transição de um compartimento para o outro, que ocasiona uma elevação acentuada da velocidade ascensional, o efetivo retorno do lodo ao fundo do reator só será possível se houver a formação de flocos maiores, que sejam capazes de vencer a velocidade ascensional nas aberturas de passagem (VAN HAANDEL et al., 2015). Dessa forma, essa região pode ser considerada como a mais crítica para o retorno do lodo. Comparativamente, a NBR 12209/2011 prevê que as velocidades no compartimento de digestão sejam inferiores a $1,20 \mathrm{~m} / \mathrm{h}$, quando da passagem da vazão máxima, enquanto na abertura de passagem esses valores não devem ser superiores a $4,0 \mathrm{~m} / \mathrm{h}$, o que corresponde ao aumento de $233 \%$ em relação ao primeiro. De acordo com Van Haandel et al. (2015), a inclinação empregada nas paredes do separador é um dos aspectos-chave desse processo. Isso porque, se por um lado, maiores inclinações facilitam o deslizamento do lodo sedimentado em direção à abertura de passagem, por outro, dificultam a formação de flocos maiores, que são efetivamente capazes de vencer a força de arraste nessa região. Se essa floculação não ocorrer, então todas as partículas com velocidade de sedimentação inferior à velocidade na abertura de passagem eventualmente poderão deixar o reator UASB com o efluente. Dessa forma, uma redução na inclinação do separador pode favorecer a formação dos flocos maiores e o retorno do lodo para o fundo reator, desde que não haja o acúmulo de lodo no decantador por tempo prolongado, que conduzirá à produção de biogás nessa região.

Para equacionar o problema, Santos et al., (2016) relatam a necessidade de melhorias na configuração do separador trifásico do reator. $E$, nessa perspectiva, Cavalcante (2003) realizou o primeiro estudo que propôs a colocação de placas na região de decantação, para materializar um decantador de alta taxa (decantador lamelar). No estudo realizado por Van Haandel et al. (2015) os autores verificaram que o reator com decantador lamelar, com placas inclinadas a $45^{\circ}$, profundidade de 0,35 m e espaçamento de 0,07 m, apresentou uma capacidade de tratamento (fração da DQO afluente digerida no reator) equivalente ao dobro da observada em um reator UASB convencional, devido à maior massa de lodo retida. Em seguida, outra alteração desenvolvida nessa mesma linha foi a colocação de um meio suporte na região de decantação, materializando um reator híbrido (ELMITWALLI et al., 2002; DE PAULA, 2007). Apesar disso, tais alternativas não ganharam interesses práticos à época, devido aos maiores custos associados. Por outro lado, diante da carência de alternativas de maior viabilidade técnica e econômica, dos impactos que os sólidos advindos do reator vem ocasionando nas etapas de pós-tratamento, e da expectativa da produção de energia a partir do lodo retido no reator, recentemente, o uso dessas soluções começa a encontrar adeptos no meio técnico e científico (ROSA et al., 2015; CHERNICHARO et al., 2015; SANTOS et al., 2016).

Neste contexto, objetivando contribuir para supressão dessa carência tecnológica atual, que representa uma demanda premente do meio técnico, o presente trabalho teve por objetivo investigar o desempenho de uma configuração modificada de reator UASB quanto à retenção física de sólidos. A concepção do reator encontra-se no item metodologia, onde foram apresentadas todas as fundamentações pertinentes. Vale ressaltar que, diferentemente das alternativas citadas anteriormente, na presente proposta não há inserção de novos elementos no reator, mas tão somente uma mudança na geometria do separador trifásico, o que significa que essa configuração, a priori, não ensejará elevação nos custos do reator. $\mathrm{Na}$ verdade, vislumbra-se uma possível redução dos custos, uma vez que as modificações seguem na direção da eliminação dos defletores de gases, que, em muitos casos, têm apresentado problemas de entupimentos e rompimentos em escala real (GASPERI, 2012). 


\section{METODOLOGIA}

\section{Reatores Experimentais}

O trabalho experimental foi realizado na Estação de Tratamento de Esgoto de Ouro Branco-Minas Gerais, da Companhia de Saneamento de Minas Gerais COPASA, onde foram instalados dois reatores UASB em escala semidemonstração, confeccionados em fibra de vidro em formato cilíndrico, com diâmetro de 1000 mm. Um deles consistia em um reator $U A S B$ convencional $(\mathrm{RC})$, utilizado como reator controle, e outro, o protótipo de teste, denominado reator modificado (RM).

O funcionamento do reator modificado é semeIhante ao reator convencional, conforme ilustrado na Figura 1, que apresenta uma representação esquemática detalhada da sua configuração. $\mathrm{Na}$ referida figura foi incluída também a configuração de um reator UASB convencional, de modo a facilitar a comparação dos dois projetos. No projeto do reator RM, foram feitas as seguintes mo-

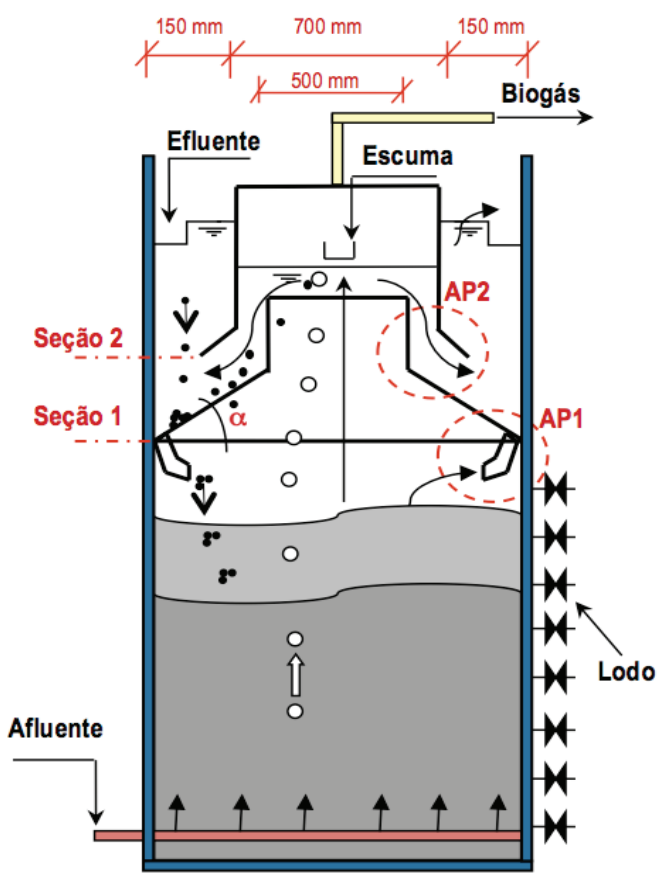

LEGENDA

REATOR UASB MODIFICADO - RM

AP1 - Abertura de passagem direta do esgoto do compartimento de digestão para o compartimento de decantação e de retorno do lodo;

AP2 - Abertura de passagem do esgoto do compartimento de digestão para o compartimento de decantação, passando pelo interior do separador trifásico. dificações, a saber: i) redução da velocidade na abertura de passagem, realizada com a divisão do separador em duas partes (coifa com extremidade superior aberta + campânula de gases sobreposta à coifa), e a criação de uma nova abertura de passagem para o decantador; ii) redução no ângulo de inclinação da parte inclinada (coifa); iii) elevação da altura do separador trifásico em relação ao fundo do reator; iv) união de duas coifas adjacentes; e v) a inserção de dispositivos para retorno do lodo na porção inferior da coifa (com um determinado espaçamento ao longo do seu comprimento, e não de forma contínua como no caso do reator convencional) em substituição aos defletores de gases. Essa modificação também teve por objetivo favorecer o escoamento do esgoto pelo interior do separador trifásico, de modo que a principal abertura de passagem para o decantador estivesse em uma posição mais elevada em relação ao fundo do reator.

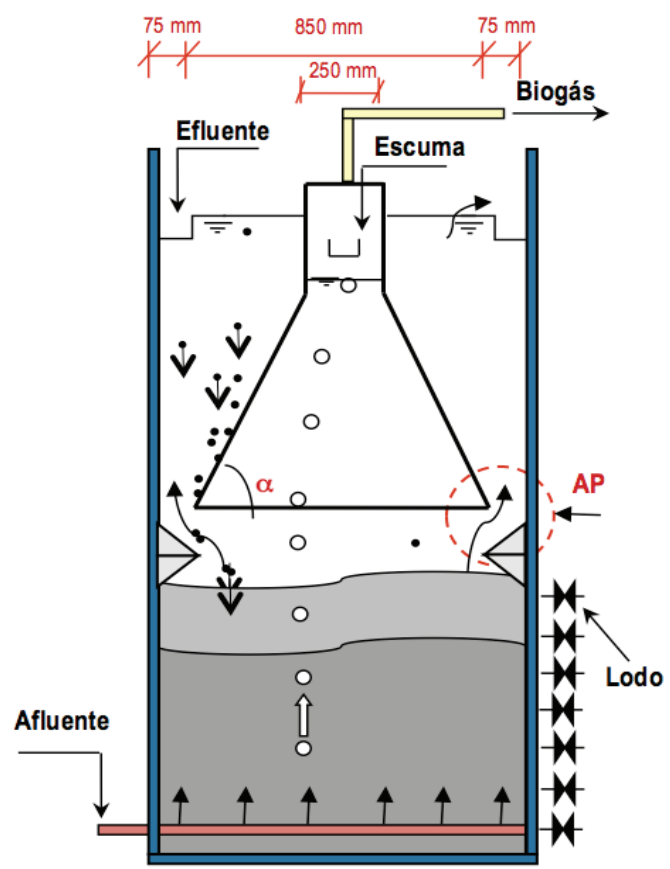

REATOR UASB CONVENCIONAL - RC

AP - Área de passagem do esgoto da câmara de digestão para o compartimento de decantação e de retorno do lodo;

个esgoto $\overbrace{\text { biogás }} \vartheta_{\text {LODO }}$

Figura 1 - Representação esquemática da configuração interna dos reatores RM e RC e identificação dos elementos componentes. 
Os reatores foram dimensionados segundos os critérios da NBR 12209/2011, mas não plenamente no caso do reator RM, em virtude da avaliação das inovações propostas. Na Tabela 1, são apresentados os valores dos parâmetros empregados no projeto dos reatores experimentais e os limites estabelecidos pela norma, a título de referência. Em essência, no projeto do reator modificado, não foram atendidos os valores de norma referentes à profundidade mínima, a inclinação do separador e a taxa de escoamento superficial para vazão máxima (TESQm) no compartimento de decantação. Comparado ao reator convencional, a profundidade do decantador foi $30 \%$ inferior, a inclinação do separador, $10 \%$, enquanto a taxa de escoamento superficial foi $83 \%$ superior. De acordo com as informações da Tabela 1, constata-se que o projeto do decantador do reator RM foi bastante crítico, apresentando ainda um tempo de detenção hidráulica (TDH) 27\% inferior ao reator RC. Por outro lado, em razão da maior altura do separador, o reator RM apresentou maior volume do compartimento de digestão. No entanto, essa diferença (9\%) não foi tão elevada, uma vez que o volume interno do separador do reator convencional também faz parte desse compartimento, e compensou a diferença entre as alturas.

Tabela 1 - Principais parâmetros de projeto dos reatores UASB experimentais e limites estabelecidos pela NBR 12209.

\begin{tabular}{|c|c|c|c|c|}
\hline Compartimento & Característica & NBR 12209 & RC & RM \\
\hline \multirow{4}{*}{$\begin{array}{l}\text { Digestão } \\
+ \\
\text { Decantação }\end{array}$} & Qmédia (m³/h) & - & 0,46 & 0,46 \\
\hline & Volume $\left(\mathrm{m}^{3}\right)$ & - & 3,69 & 3,69 \\
\hline & TDH médio - Temperatura do esgoto $\left(18^{\circ} \mathrm{C}-21^{\circ} \mathrm{C}\right)$ & 8,00 & 8,00 & 8,00 \\
\hline & Profundidade útil total $(\mathrm{m})$ & $4,00-6,00$ & 4,65 & 4,65 \\
\hline \multirow{5}{*}{ Digestão } & Volume $\left(\mathrm{m}^{3}\right)$ & - & 2,77 & 3,02 \\
\hline & TDH médio (h) & - & 6,00 & 6,54 \\
\hline & Profundidade mínima (m) & 2,50 & 3,15 & 3,60 \\
\hline & Velocidade ascensional para Qmédia (m/h) & $\leq 0,70$ & 0,59 & 0,59 \\
\hline & Velocidade ascensional para Qmáxima & $\leq 1,20$ & 0,87 & 0,87 \\
\hline \multirow{7}{*}{ Decantação } & Volume $\left(\mathrm{m}^{3}\right)$ & - & 0,92 & 0,67 \\
\hline & TDH para Q̨média (h) & $\geq 1,50$ & 2,00 & 1,46 \\
\hline & TDH para Qmáxima (h) & $\geq 1,00$ & 1,33 & 0,97 \\
\hline & Profundidade total mínima (m) & 1,50 & 1,50 & 1,05 \\
\hline & Profundidade mínima parede vertical (m) & 0,30 & 0,60 & 0,48 \\
\hline & Taxa de escoamento superficial para Qmáxima (m³/m².h) & $\leq 1,20$ & 0,94 & 1,72 \\
\hline & Inclinação da parede inclinada $\alpha\left(^{\circ}\right)$ & $\geq 50$ & 70 & 45 \\
\hline
\end{tabular}

\section{CONDIÇÕES OPERACIONAIS}

Os reatores foram operados diariamente conforme o hidrograma de vazão afluente apresentado na Figura 2, com o intuito de simular as condições reais de funcionamento em uma ETE. Para consecução destas variações, foram instalados dois temporizadores e um inversor de frequências. Os acréscimos na vazão corresponderam a $1,15(0,53$ $\left.\mathrm{m}^{3} / \mathrm{h}\right), 1,30\left(0,60 \mathrm{~m}^{3} / \mathrm{h}\right)$ e $1,50\left(0,69 \mathrm{~m}^{3} / \mathrm{h}\right)$ da vazão média de projeto dos reatores $\left(0,46 \mathrm{~m}^{3} / \mathrm{h}\right)$.
Além disso, foi instalado um horâmetro que permitiu quantificar o tempo real de operação dos reatores. Tal equipamento se fez necessário, pois o sistema de esgotos de Ouro Branco apresenta três estações elevatórias, de maneira que, durante a madrugada (entre $3 \mathrm{~h}$ e $6 \mathrm{~h}$ da manhã), é comum que não haja vazão afluente à ETE-Ouro Branco, assim como também são comuns paradas para manutenções. 


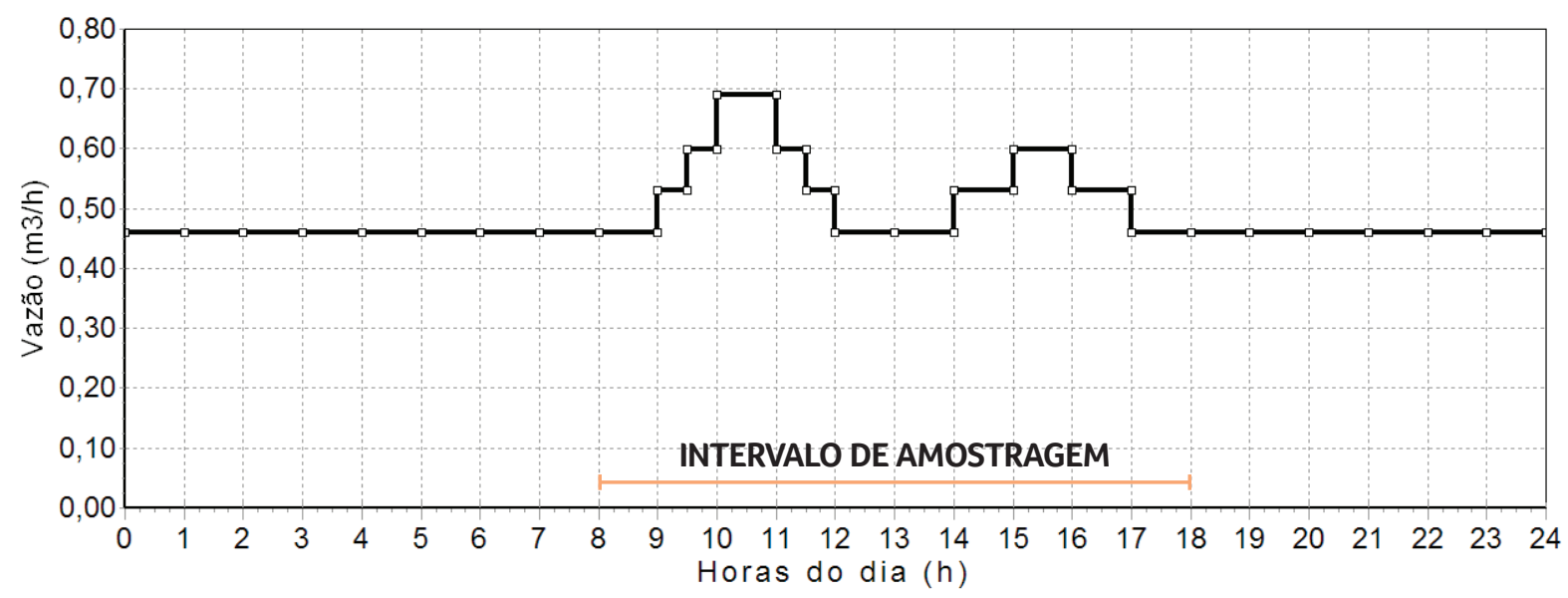

Figura 2 - Hidrograma do esgoto bruto afluente aos reatores durante as etapas de operação.

Os experimentos foram conduzidos em duas etapas operacionais, conforme detalhado na sequência, e o lodo dos reatores encontravam-se plenamente adaptados, estando em operação há mais de sete meses nessas mesmas condições. Em cada uma das etapas, o reator foi operado com diferentes dimensões da área de passagem da zona de digestão para zona de decantação AP1, com o objetivo de avaliar o efeito da redução da velocidade na retenção física do lodo.

A área total de passagem AP1 foi confeccionada com joelhos plásticos de $45^{\circ}$ e diâmetro de $50 \mathrm{~mm}$, de forma a concordar com o ângulo de inclinação do separador (de $45^{\circ}$ ), resultando em um ângulo total de $90^{\circ}$ nas áreas de passagem. Dessa forma, foi possível impedir o acesso do biogás ao compartimento de decantação e, ao mesmo tempo, garantir condições favoráveis ao retorno, que esteve condicionado ao deslizamento por duas superfícies com inclinação de $45^{\circ}$, de direções opostas. Ressalta-se que durante todos os experimentos não foram observadas obstruções nos joelhos, porém, considerando a aplicação dessa solução em escala real, o diâmetro de 50 $\mathrm{mm}$ pode não ser o mais apropriado. Por outro lado, é importante apenas que a área AP1 deva ser bem inferior à área AP2, para que haja o fluxo preferencial por essa última. $\mathrm{Na}$ continuidade do desenvolvimento desse reator, estão sendo ava- liadas outras tipologias para a área de passagem AP1 (no momento estão sendo testadas aberturas retangulares).

\section{Etapa 1}

O reator RM foi operado com uma área de passagem AP1 total de 0,035 $\mathrm{m}^{2}$, confeccionada com 18 joelhos de $45^{\circ}$ em PVC, com diâmetro de 50 $\mathrm{mm}$, espaçados a cada $120 \mathrm{~mm}$, e área AP2 de $0,196 \mathrm{~m}^{2}$, perfazendo uma área total de 0,231 $\mathrm{m}^{2}$; já o reator $\mathrm{RC}$ apresentou área total de passagem de $0,218 \mathrm{~m}^{2}$.

\section{Etapa 2}

O reator RM foi operado com uma área de passagem AP1 total de 0,061 $\mathrm{m}^{2}$, confeccionada com 31 joelhos de $45^{\circ}$ em PVC, com diâmetro de $50 \mathrm{~mm}$, espaçados a cada $51 \mathrm{~mm}$, e área AP2 de 0,196 m², perfazendo uma área total de $0,257 \mathrm{~m}^{2}$; já o reator $\mathrm{RC}$ apresentou área total de passagem de 0,218 $\mathrm{m}^{2}$.

A estimativa das velocidades nas aberturas de passagem AP1 e AP2 no reator RM foi realizada considerando as seguintes hipóteses de cálculo: i) o tempo de detenção hidráulica (ou tempo de percurso) da parcela do esgoto que escoa pelo interior do separador e atinge o decantador passando pela área AP2 é igual ao tempo de detenção da parcela que escoa através das áreas de passagem AP1; ii) esse tempo corresponde ao interva- 
lo de escoamento entre as seções de controle $1 \mathrm{e}$ 2 (Figura 1); iii) o escoamento ocorre em regime laminar, sendo desprezíveis as perdas de carga localizadas; iv) o fluxo na parte interna se processa de forma independente do fluxo gasoso. Com base nessas considerações, estimou-se que 19\% do fluxo ocorrem através das áreas de passagem AP1, e $81 \%$ pelo interior do separador, passando por AP2. Dessa forma, e com base nas áreas de passagem, as velocidades nas aberturas de passagem foram estimadas.

A Tabela 2 apresenta um resumo das características operacionais dos reatores experimentais para as duas etapas operacionais, com destaque para os valores das velocidades nas aberturas de pas- sagem nos dois reatores. De acordo com a NBR $12209 / 2011$, essas velocidades devem ser inferiores a 2,0 m/h, para vazão média, e 4,0 m/h, para vazão máxima. Assim, observa-se que na Etapa 1, o reator RM apresentou velocidade com essa ordem de grandeza, na passagem AP1 (que é de fato a abertura por onde o lodo poderá retornar para o fundo do reator), porém, sendo $13 \%$ superior em relação ao reator RC. Nestas condições, foi possível avaliar o impacto das condições críticas de projeto do decantador no reator RM. Já na Etapa 2, as velocidades na área AP1 foram reduzidas com o objetivo de avaliar se o retorno do lodo seria favorecido.

Tabela 2 - Características operacionais dos reatores em cada Etapa operacional.

\begin{tabular}{|c|c|c|c|c|c|c|c|c|}
\hline \multirow{4}{*}{ Etapa } & \multirow{4}{*}{$\begin{array}{l}\text { Tempo de duração } \\
\text { (d) }\end{array}$} & \multirow{4}{*}{$\begin{array}{l}\text { Configuração } \\
\text { do reator modificado }\end{array}$} & \multicolumn{6}{|c|}{ Velocidade nas aberturas de passagem para o decantador $(\mathrm{m} / \mathrm{h})$} \\
\hline & & & \multicolumn{3}{|c|}{ Média } & \multicolumn{3}{|c|}{ Máxima } \\
\hline & & & \multicolumn{2}{|c|}{ RM } & RC & \multicolumn{2}{|c|}{ RM } & RC \\
\hline & & & AP1 & AP2 & AP & AP1 & AP2 & AP \\
\hline 1 & 105 & 1 & 2,41 & 1,22 & 2,12 & 3,62 & 1,83 & 3,18 \\
\hline 2 & 71 & 2 & 1,40 & 1,22 & 2,12 & 2,10 & 1,83 & 3,18 \\
\hline
\end{tabular}

PARÂMETROS DE MONITORAMENTO EM

\section{CAMPO E LABORATORIAIS}

O monitoramento da fase líquida constou da coleta de amostras compostas no intervalo de 10 horas (entre o período de $8 \mathrm{~h}$ às $18 \mathrm{~h}$ ), com frequência de duas vezes na semana, do esgoto bruto e dos efluentes dos reatores. De cada alíquota coletada a cada uma hora, foram medidos o $\mathrm{pH}$ e a temperatura. As amostras coletadas foram conservadas em geladeira e posteriormente levadas ao laboratório, utilizando um isopor com gelo, preservando-as assim à $4^{\circ} \mathrm{C}$ até o momento da análise. Em laboratório foram analisados os parâmetros DQQ , DQO filtrada, SST, SSV de acordo com Standard Methods of Examination of Water and Wastewater (APHA, 2012).

O lodo foi coletado em diferentes pontos amostrais posicionados ao longo da altura de cada rea- tor (ver Figura 2), sendo oito pontos no RM, devido ao maior volume do seu compartimento de digestão, e sete pontos no RC, e caracterizados em termos de ST e STV para avaliação da massa de sólidos retida nos dois reatores. A coleta era realizada com frequência quinzenal, e a massa de lodo foi então obtida a partir da concentração do lodo e do volume de influência do ponto amostral.

A produção de biogás foi medida em campo no intervalo de 24 horas, por meio de gasômetros (LAO/G1), e a produção de metano foi obtida considerando-se um percentual de aproximadamente $70 \%$ de metano no biogás.

\section{RESULTADOS}

\section{Dados operacionais}

No que diz respeito às condições operacionais dos reatores, é importante esclarecer que as va- 
riações previstas na vazão afluente (Figura 2) fizeram com que o TDH fosse reduzido de 8,00 h (valor de projeto) para 7,53 h. Por outro lado, devido às eventuais paradas nas estações elevatórias que enviam os esgotos até a ETE-Ouro Branco (pela redução na geração de esgoto ou manutenções), a alimentação dos reatores, muitas vezes, não ocorreu durante todo o dia. E, nestes casos, o TDH real superou o valor de projeto $(>8,00)$. Nos experimentos realizados, o tempo de alimentação dos reatores foi, em média, de $21 \mathrm{~h} / \mathrm{dia}$, para ambas as etapas operacionais.
Na Tabela 3, são apresentados estes resultados do TDH efetivo, em termos de estatística descritiva básica, assim como informações sobre os parâmetros $\mathrm{pH}$ e temperatura do esgoto bruto e dos efluentes dos reatores. Com relação a estes dois parâmetros, foram observados valores típicos para o pH do esgoto bruto e dos efluentes dos reatores (Tabela 3), com baixíssimas variações. Quanto às temperaturas médias do líquido, em ambas as etapas, as mesmas foram da ordem de $25^{\circ} \mathrm{C}$.

Tabela 3 - Dados operacionais do Esgoto Bruto e dos efluentes dos reatores RM e RC.

\begin{tabular}{|c|c|c|c|c|c|c|c|c|c|c|c|c|}
\hline & \multicolumn{6}{|c|}{ ETAPA 1} & \multicolumn{6}{|c|}{ ETAPA 2} \\
\hline & \multicolumn{12}{|c|}{ ESGOTO BRUTO } \\
\hline Parâmetro & $\mathrm{n}$ & Média & Mediana & Min & Max & Sx & $\mathrm{n}$ & Média & Mediana & Min & Max & Sx \\
\hline Temperatura $\left({ }^{\circ} \mathrm{C}\right)$ & 31 & 24,9 & 24,8 & 23,3 & 26,3 & 0,74 & 20 & 24,8 & 24,6 & 23,0 & 26,6 & 1,23 \\
\hline \multirow[t]{2}{*}{$\mathrm{pH}$} & 31 & 7,13 & 7,12 & 6,92 & 7,33 & 0,11 & 20 & 7,30 & 7,32 & 7,09 & 7,46 & 0,09 \\
\hline & \multicolumn{12}{|c|}{ REATOR MODIFICADO } \\
\hline Temperatura $\left({ }^{\circ} \mathrm{C}\right)$ & 31 & 25,0 & 25,0 & 22,3 & 27,3 & 1,16 & 20 & 24,2 & 24,2 & 26,8 & 21,9 & 1,68 \\
\hline $\mathrm{pH}$ & 31 & 6,93 & 6,92 & 6,80 & 7,16 & 0,09 & 20 & 7,10 & 7,09 & 7,00 & 7,26 & 0,07 \\
\hline \multirow[t]{2}{*}{ TDH (h) } & 31 & 8,87 & 8,14 & 7,17 & 15,01 & 2,07 & 20 & 8,83 & 8,16 & 7,32 & 13,88 & 1,83 \\
\hline & \multicolumn{12}{|c|}{ REATOR CONVENCIONAL } \\
\hline Temperatura $\left({ }^{\circ} \mathrm{C}\right)$ & 31 & 25,0 & 25,1 & 22,6 & 27,2 & 1,05 & 20 & 24,4 & 24,5 & 21,9 & 26,6 & 1,62 \\
\hline $\mathrm{pH}$ & 31 & 6,88 & 6,77 & 6,74 & 7,08 & 0,10 & 20 & 7,07 & 7,08 & 6,94 & 7,24 & 0,08 \\
\hline $\mathrm{TDH}(\mathrm{h})$ & 31 & 8,82 & 8,05 & 7,14 & 15,01 & 2,08 & 20 & 8,83 & 8,16 & 7,15 & 12,39 & 1,63 \\
\hline
\end{tabular}

\section{AVALIAÇÃO NA RETENÇÃO DE SÓLIDOS}

SST no efluente

Na primeira análise de desempenho dos reatores quanto à retenção de sólidos, é feita uma avaliação isolada das concentrações de SST no efluente, uma vez que os sistemas de tratamento são avaliados com base na redução das concentrações. Nas Figuras 3 e 4, são apresentadas as séries temporais de SST do esgoto bruto e dos efluentes dos reatores nas Etapas 1 e 2. Na primeira etapa, o EB apresentou concentração mediana de 456 mgSST/L, e os reatores RM e RC, de $88 \mathrm{mgSST} / \mathrm{L}$ e 106 $\mathrm{mgSST} / \mathrm{L}$, nessa ordem. Isso significa que houve uma redução de $17 \%$ nas concentrações efluen- tes de SST no reator RM em relação ao reator RC. Considerando a mediana das eficiências marginais observadas, a remoção de sólidos no reator RM foi de $80 \%$, e no reator RC foi de $76 \%$. Na segunda etapa, as concentrações medianas de SST no esgoto bruto e nos efluentes dos reatores RM e $\mathrm{RC}$ foram, respectivamente, de $416 \mathrm{mg} / \mathrm{L}, 73 \mathrm{mg} / \mathrm{L}$ e $82 \mathrm{mg} / \mathrm{L}$. Comparativamente, houve uma redução de $11 \%$ nas concentrações efluentes do reator $\mathrm{RM}$ em relação ao reator $\mathrm{RC}$. Já as medianas das eficiências marginais nos reatores foram de $82 \%$ (RM) e 76\% (RC). Esses resultados permitem afirmar que o desempenho do reator RM foi superior ao reator $\mathrm{RC}$, em ambas as etapas. 


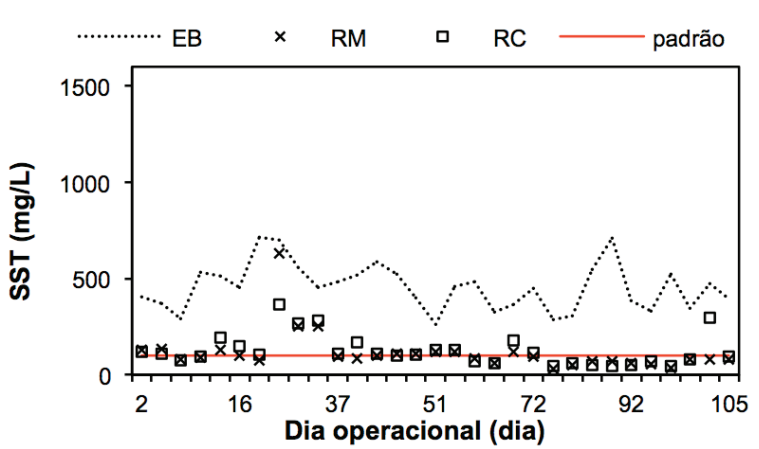

Figura 3 - Série temporal de SST do esgoto bruto e dos efluentes dos reatores RM e RC na Etapa 1.

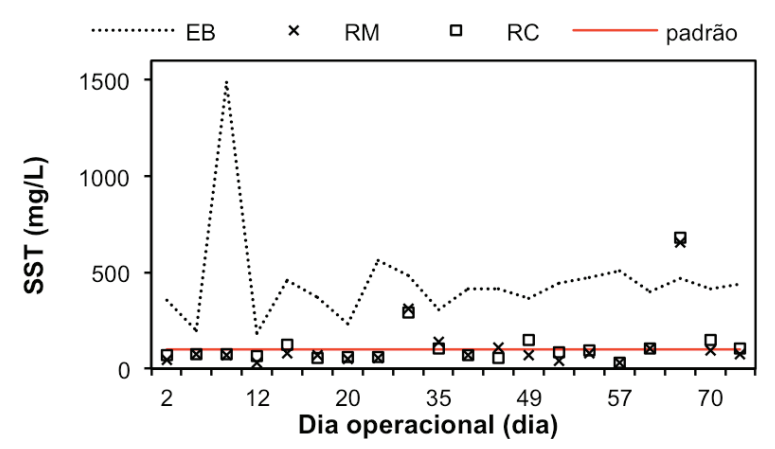

Figura 4 - Série temporal de SST do esgoto bruto e dos efluentes dos reatores RM e RC na Etapa 2.

Analisando o desempenho dos reatores à luz do atendimento ao padrão de lançamento de efluentes de $100 \mathrm{mgSST} / \mathrm{L}$ (Figuras 5 e 6), na primeira etapa (Figura 5), o reator RM atendeu o padrão em $65 \%$ das amostras coletadas, enquanto no reator $\mathrm{RC}$ o percentual de atendimento foi de $45 \%$. Já na segunda etapa (Figura 6), o percentual de atendimento em ambos os reatores aumentou em relação à etapa anterior, provavelmente devido às menores concentrações de SST no esgoto bruto afluente. Mesmo assim, o reator RM apresentou melhor desempenho, com atendimento em 75\% das amostras coletadas, enquanto no reator RC esse percentual foi de $60 \%$. Na primeira etapa o percentual de atendimento ao padrão. Esses resultados permitem afirmar que o reator RM apresentou maior confiabilidade no atendimento ao padrão, em relação ao reator RC, em ambas as etapas.

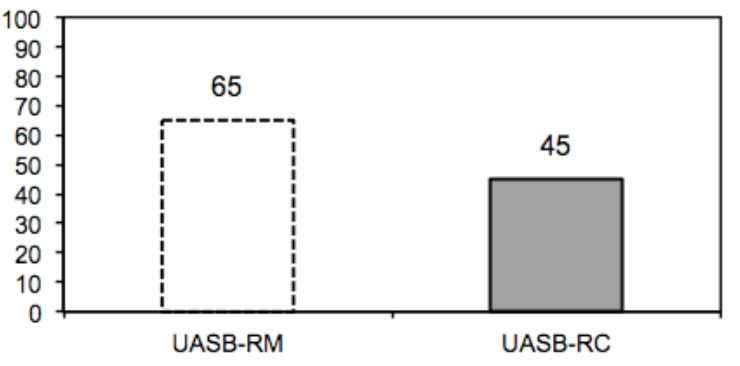

Figura 5 - Percentual de atendimento ao padrão de lançamento de SST dos reatores RM e RC na Etapa 1.

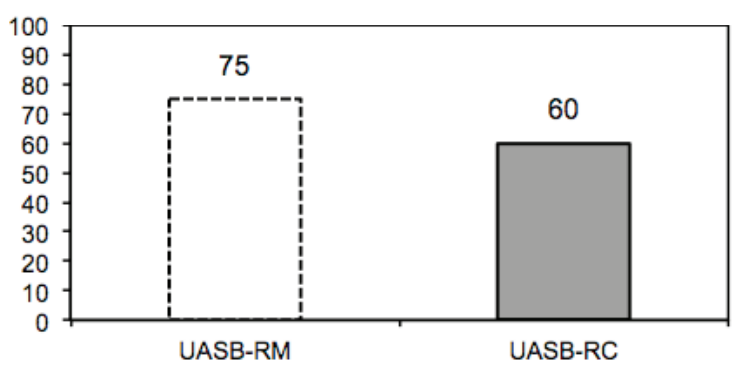

Figura 6 - Percentual de atendimento ao padrão de lançamento de SST dos reatores RM e RC na Etapa 2.

Diante desses resultados é possível concluir que as condições críticas de projeto do compartimento de decantação não conduziram à perda de desempenho do reator RM na retenção de sólidos. Contrariamente a esse fato, houve um melhor desempenho desse reator. Dessa forma, todos os aspectos que foram modificados no projeto do reator RM e que podem atuar no sentido de favorecer a retenção de sólidos, em algum grau, podem ter contribuído para esses resultados. Entre estes, a maior altura do separador, que minimiza o efeito da expansão da manta de lodo (LEITÃO, 2004); a menor velocidade na abertura de passagem AP2, que favorece a sedimentação dos sólidos arrastados pelo fluxo que percorreu a parte interna do separador; e a menor inclinação do separador, que favorece a formação de flocos maiores, dotados de maior sedimentabilidade (VAN HAANDEL et al., 2015).

Com relação ao ganho de desempenho que poderia ser alcançado com redução da velocidade 
na abertura AP1 na Etapa 2, não houve um indício claro da ocorrência desse efeito, com esses resultados. Entretanto, é possível que essa constatação tenha sido ocultada pela redução das concentrações de SST no efluente do reator RC, em consequência das menores concentrações no esgoto bruto. Conforme será mostrado adiante, os resultados da produção de metano parecem sustentar de forma clara essa hipótese.

\section{SSV NO EFLUENTE}

O parâmetro sólidos suspensos voláteis (SSV) é comumente utilizado como indicador da parcela da biomassa que deixa o reator com o efluente final, e também com uma medida da quantidade de matéria orgânica particulada presente no esgoto bruto. Nas Figuras 7 e 8 observa-se um comportamento similar dos dois reatores, nas séries temporais de SSV, de maneira semelhante ao parâmetro SST. Considerando os resultados em termos da mediana, nas Etapas 1 e 2, foram observados valores, respectivamente, de $362 \mathrm{mg} / \mathrm{L}$ e $347 \mathrm{mg} / \mathrm{L}$ no $E B$, de $68 \mathrm{mg} / \mathrm{L}$ e $54 \mathrm{mg} / \mathrm{L}$ no reator RM, e 77 $\mathrm{mg} / \mathrm{L}$ e $63 \mathrm{mg} / \mathrm{L}$ no reator RC. Nesse caso houve uma redução de 11\% na Etapa 1, e 14\% na Etapa 2 nas concentrações efluentes de SSV do reator RM em relação ao reator RC.

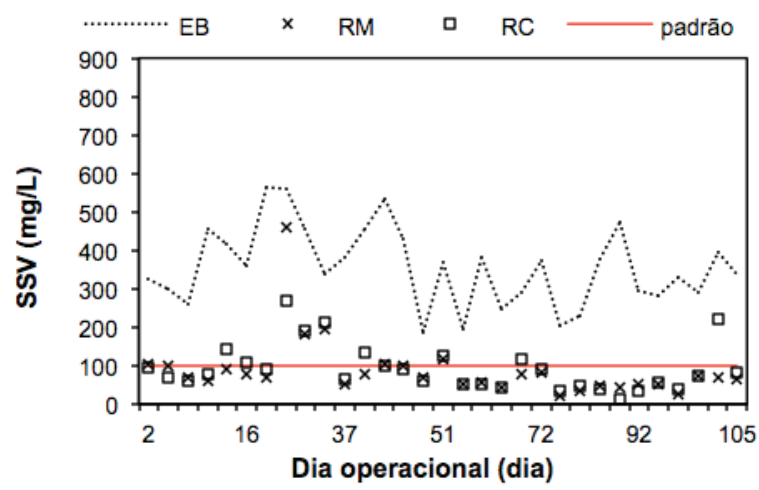

Figura 7 - Série temporal de SSV do esgoto bruto e dos efluentes dos reatores RM e RC na Etapa 1.

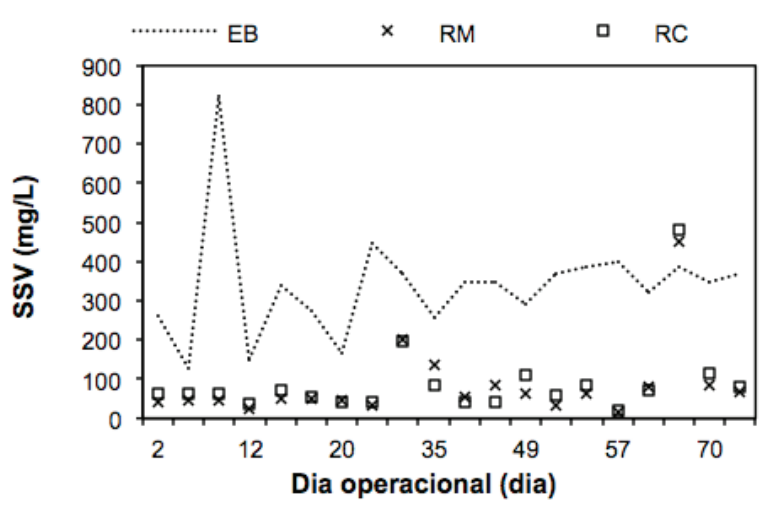

Figura 8 - Série temporal de SSV do esgoto bruto e dos efluentes dos reatores RM e RC na Etapa 2.

Como não há um padrão de lançamento para esse parâmetro, foi feita uma comparação do desempenho entre os dois reatores, considerando a frequência de amostras em que um reator apresentou concentrações efluentes inferiores ao outro. Os resultados dessa análise estão apresentados nos gráficos das Figuras 9 e 10. Conforme se pode observar, na Etapa 1, o reator RM apresentou menores concentrações de SSV no efluente em $61 \%$ das amostras coletadas, e o reator RC, em apenas $39 \%$. Na Etapa 2, o percentual no reator RM aumentou para $65 \%$ e, consequentemente, no reator RC foi reduzido para $35 \%$. Dessa forma, o percentual de amostras em que o reator RM apresentou menores concentrações de SSV foi $56 \%$ superior ao percentual observado no reator RC, na Etapa 1, e se elevou para $86 \%$ na Etapa 2. E, neste caso, é possível pensar que a elevação desse percentual na Etapa 2 esteja sinalizando na direção da confirmação do benefício produzido pela redução da velocidade na abertura AP1.

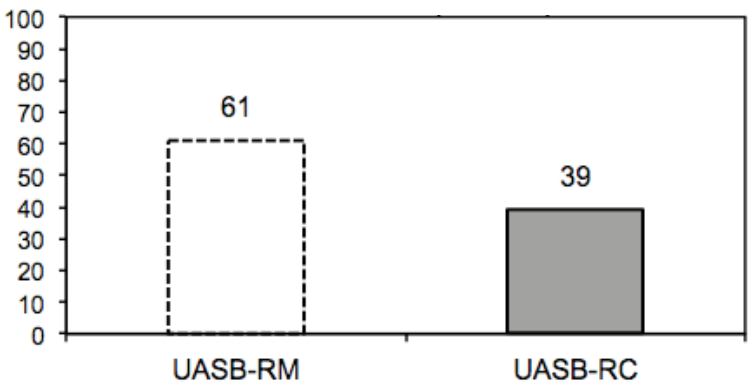

Figura 9 - Percentual de amostras que as concentrações de SSV foram inferiores ao outro reator (RMx RC) na Etapa 1. 


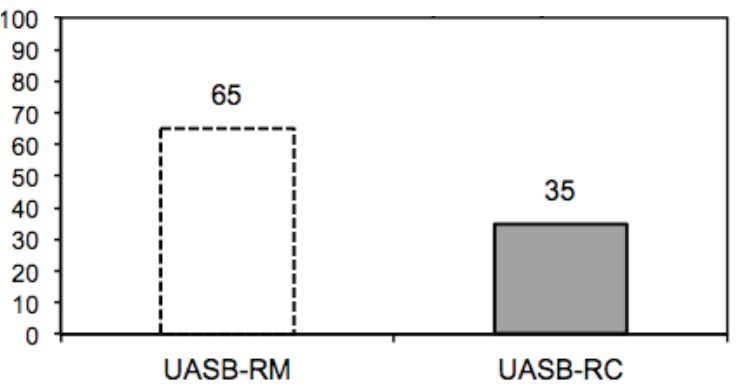

Figura 10 - Percentual de amostras que as concentrações de SSV foram inferiores ao outro reator $(\mathrm{RM} \times \mathrm{RC})$ na Etapa 2.

\section{SST RETIDOS NO REATOR}

Em um dado intervalo de tempo, a produção total de lodo pode ser considerada como sendo a massa de sólidos acumulada no reator, acrescida da massa perdida no efluente final. Quando o reator atinge sua capacidade máxima de retenção de sólidos, diz-se que o reator encontra-se cheio de lodo, e a produção se iguala à parcela de sólidos perdida com o efluente. Nestas condições, a eficiência de retenção de sólidos se anula e, caso as concentrações de sólidos comprometam o atendimento aos padrões ambientais, há a necessidade de se realizar um descarte de lodo do reator, a fim de que uma parcela dos sólidos descarregados com o efluente possa ficar retida no reator, e que as concentrações de sólidos no efluente sejam diminuídas (VAN HAANDEL \& LETTINGA, 1994).

Nos gráficos das Figuras 11 e 12 são apresentados os resultados da eficiência de retenção de sólidos nos reatores, obtidas conforme supracitado. Os gráficos foram construídos a partir da variação da massa de lodo obtida em duas coletas de amostras sucessivas, e das cargas medianas de SST no efluente. Foi considerado que as concentrações de SST no lodo eram iguais às concentrações ST, em virtude da dificuldade de se filtrar o lodo, que é uma hipótese legítima. Na Etapa 1, foram realizados três descartes de lodo, com intervalos variando entre 30 e 40 dias, e o número de dados utilizados no cálculo das eficiências foi igual a $6 . \mathrm{Na}$
Etapa 2, foram realizados dois descartes de lodo, com os mesmos intervalos praticados na Etapa 1, e o número de dados utilizados no cálculo das eficiências foi igual a 4. Na Etapa 1, a eficiência mediana foi $45,5 \%$ no reator RM, e de $39,9 \%$ no reator convencional. Já na Etapa 2, as eficiências foram um pouco mais elevadas, em ambos os reatores, sendo de 50,2\% (RM) e 46,7\% (RC). Além da análise dos valores medianos, é possível observar nos gráficos Box-plot a tendência do reator RM apresentar maiores eficiências de retenção de sólidos em relação ao reator RC, notadamente, na Etapa 1. Esses resultados corroboram as observações realizadas anteriormente, permitindo atestar o melhor desempenho do reator RM e o funcionamento das modificações realizadas, mesmo que esse reator tenha sido projetado e operado em condições mais críticas no compartimento de decantação.

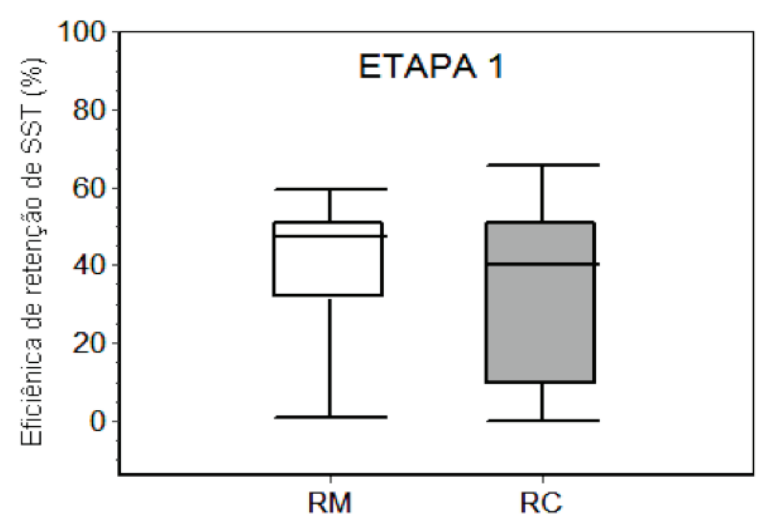

Figura 11 - Gráfico Box-plot das eficiências de retenção de lodo nos reatores RM e RC na Etapa 1.

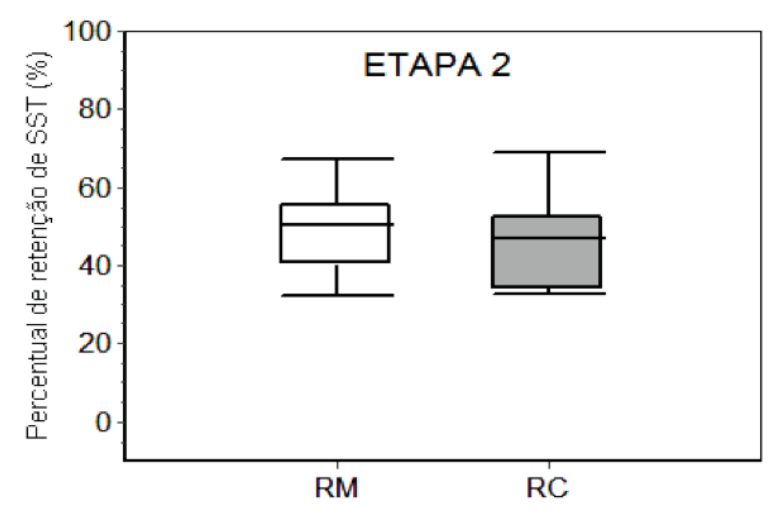

Figura 12 - Gráfico Box-plot das eficiências de retenção de lodo nos reatores RM e RC na Etapa 2. 


\section{DESEMPENHO DOS REATORES NA REMOÇÃO DE MATÉRIA ORGÂNICA \\ DQO}

Em relação às Figuras 13 e 14, nota-se que o esgoto bruto afluente à ETE-Ouro Branco tem características de um esgoto concentrado (esgoto forte), já que as concentrações de DQO observadas foram superiores aos valores típicos de 600 $\mathrm{mg} / \mathrm{L}$ comumente reportados na literatura (VON SPERLING, 2005). Na Etapa 1, o esgoto bruto apresentou concentrações de DQQOtotal variando de 678 - $1021 \mathrm{mg} / \mathrm{L}$, com valor mediano de 956 $\mathrm{mg} / \mathrm{L}$, e os efluentes dos reatores RM e RC, medianas de $220 \mathrm{mg} / \mathrm{L}$ e $223 \mathrm{mg} / \mathrm{L}$, respectivamente. Já na Etapa 2, as variações de DQOOtotal do esgoto bruto ocorreram uma faixa similar à primeira etapa, 671 - $1037 \mathrm{mg} / \mathrm{L}$, porém, a mediana foi reduzida para $779 \mathrm{mg} / \mathrm{L}$, correspondendo a uma redução percentual de $18 \%$. Respondendo a essa redução, as concentrações medianas de DQQ Ototal nos efluentes dos reatores RM e RC também registraram valores medianos menores, de $143 \mathrm{mgD}$ QO/L e 172 mgDQO/L, nessa ordem. De acordo com esses resultados, a remoção de DQO total nos dois reatores foi similar na primeira etapa e, na segunda etapa, foi superior no reator RM.

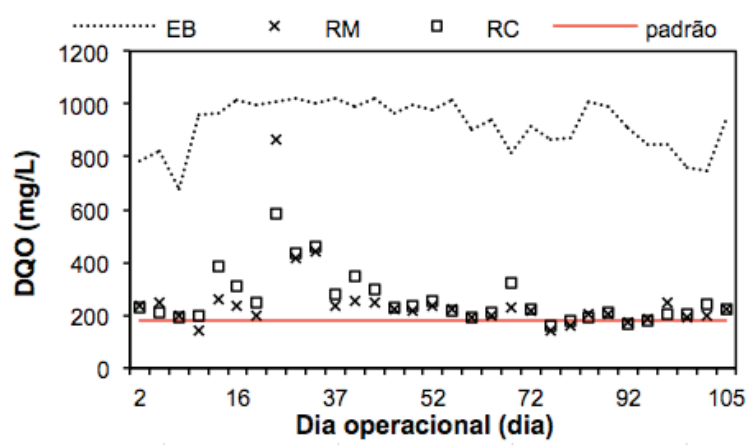

Figura 13 - Série temporal de DQQOtotal do esgoto bruto e dos efluentes dos reatores na Etapa 1.

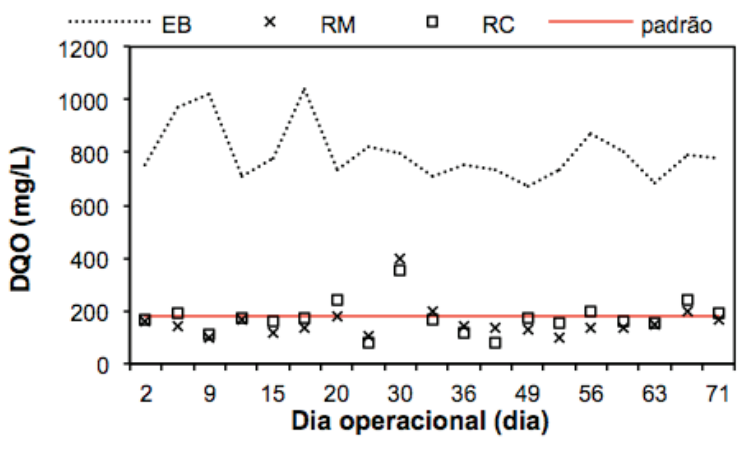

Figura 14 - Série temporal de DQQOtotal do esgoto bruto e dos efluentes dos reatores na Etapa 2.

Comparando-se o desempenho dos reatores à luz da legislação mineira de lançamento de efluentes, observa-se que os reatores, na maior parte do tempo, não atenderam ao padrão de concentração de DQOtotal, de $180 \mathrm{mg} / \mathrm{L}$, na Etapa 1. E, ao contrário, foram capazes de atender ao padrão para maioria dos resultados, na Etapa 2. Tal comportamento, associado às concentrações de DQQ do esgoto bruto local (esgoto forte), justifica a observância do critério de eficiência para os reatores, e não o critério de concentração. Neste caso, os reatores atenderam ao padrão mínimo de $55 \%$, em mais de $90 \%$ das amostras coletadas (Figuras $15 \mathrm{e}$ 16), em ambas etapas. A mediana das eficiências ao longo do monitoramento foi superior ao valor exigido de $65 \%$ pela legislação (média anual), sendo de $77 \%$ e $81 \%$, no reator RM, e de $75 \%$ e $77 \%$, no reator RC, respectivamente, nas Etapas 1 e 2.

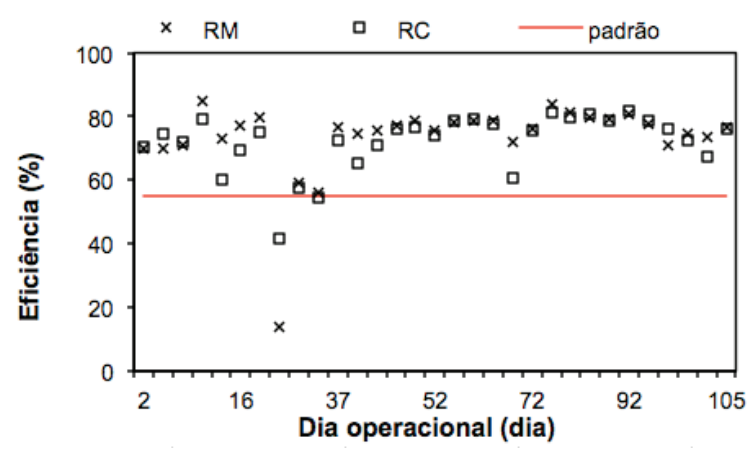

Figura 15 - Série temporal da eficiência de remoção de DQQOtotal nos reatores na Etapa 1. 


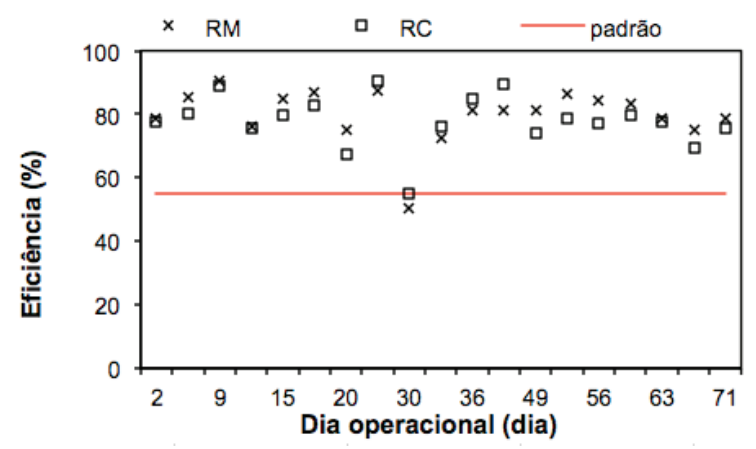

Figura 16 - Série temporal da eficiência de remoção de DQQOtotal nos reatores na Etapa 2.

A analisando a frequência de vezes em que a concentração efluente de DQOtotal de um reator foi inferior ao outro (Figuras 17 e 18), observa-se que o reator RM apresentou melhor desempenho que o reator $\mathrm{RC}$ em ambas etapas. Na etapa 1 , o reator RM apresentou menores concentrações de DQOtoal em $68 \%$ das amostras coletadas, enquanto no reator RC isso ocorreu em apenas 32\% das amostras. Na Etapa 2, além do aumento observado na eficiência mediana no reator RM, houve também um maior percentual de amostras que apresentaram menores concentrações de DQOtotal, em relação ao reator RC. Esses resultados podem ser mais um indício de que a melhoria na retenção de sólidos possa ter sido proporcionada pela redução da velocidade na abertura AP1, na Etapa 2. Independentemente disso, o reator RM apresentou desempenho superior ao reator RC, e esses resultados permitem afirmar que as alterações no projeto deste reator ofereceram os benefícios que podem ser esperados com o aumento da retenção física de sólidos, qual seja, a remoção de DQQO.

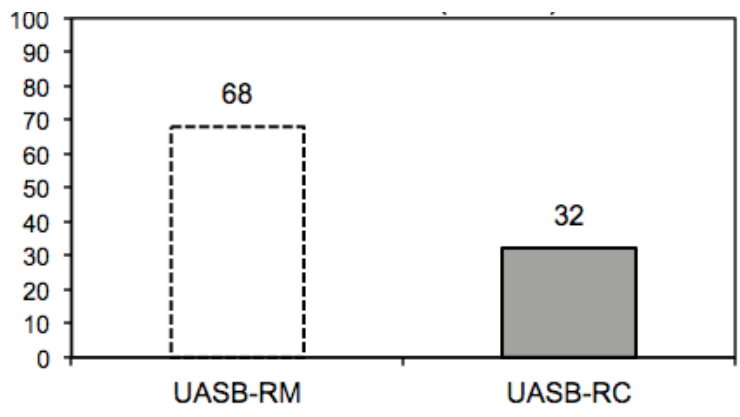

Figura 17- Percentual de amostras que as concentrações de DQQ reator $(\mathrm{RM} \times \mathrm{RC})$ na Etapa 1.

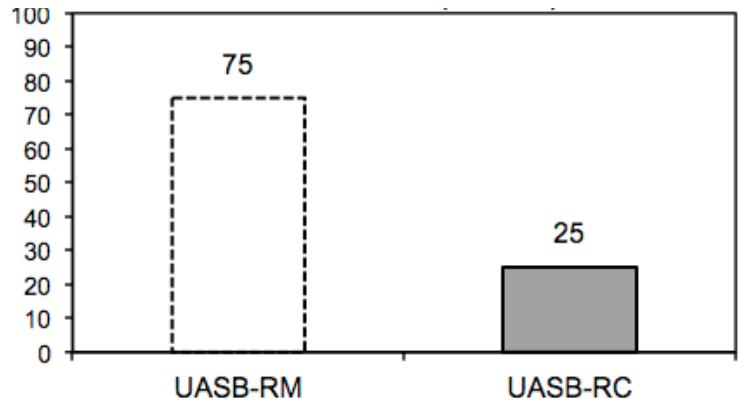

Figura 18 - Percentual de amostras que as concentrações de DQO total foram inferiores ao outro reator $(\mathrm{RM} \times \mathrm{RC})$ na Etapa 2.

\section{DQO FILTRADA}

No caso das concentrações de DQQ filtrada (Figuras 19 e 20), observou-se que os reatores apresentaram comportamentos similares, com DQO mediana total de $73 \mathrm{mg} / \mathrm{L}$ e $35 \mathrm{mg} / \mathrm{L}$ para o reator modificado; e $75 \mathrm{mg} / \mathrm{L}$ e $36 \mathrm{mg} / \mathrm{L}$ para o reator convencional, nas etapas 1 e 2 respectivamente. Estes resultados indicam que o reator modificado teve um desempenho semelhante ao convencional em ambas etapas, indicando que as modificações não ocasionaram perda de desempenho na conversão biológica de matéria orgânica, como era de se esperar. Isso porque é sabido que a limitação do desempenho não está na capacidade de conversão do substrato orgânico, mas sim na retenção física de sólidos, que é limitada pelo projeto do separador trifásico (VAN HAANDEL, et al., 2015).

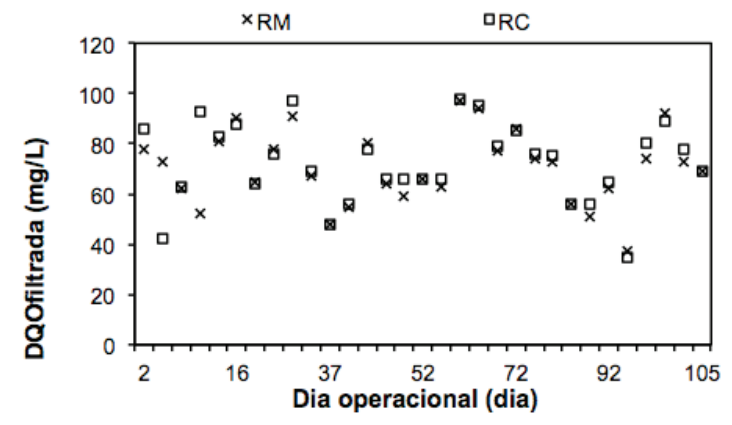

Figura 19 - Série temporal de DQ̨Ofiltrada dos efluentes dos reatores RM e RC na Etapa1. 


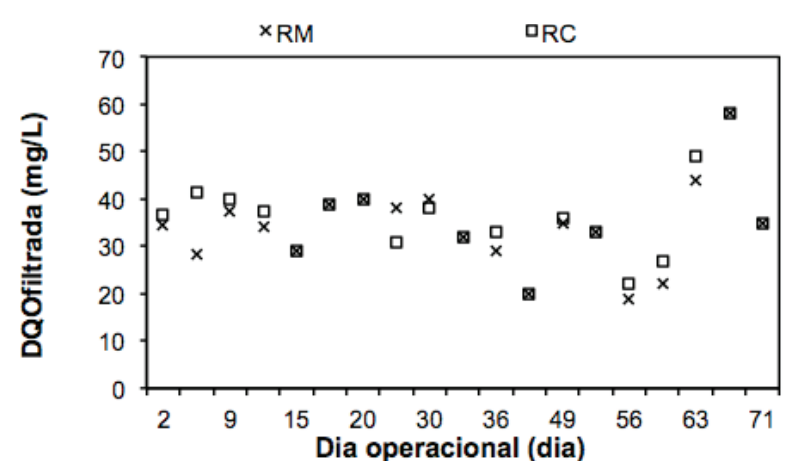

Figura 20 - Série temporal de DQ̨Ofiltrada dos efluentes dos reatores RM e RC na Etapa 2.

Em relação à eficiência biológica (Figuras 21 e 22), os valores medianos foram de $92 \%$ em ambos os reatores, na Etapa 1, e, na Etapa 2, foram ligeramente elevadas para o patamar de $95 \%$.

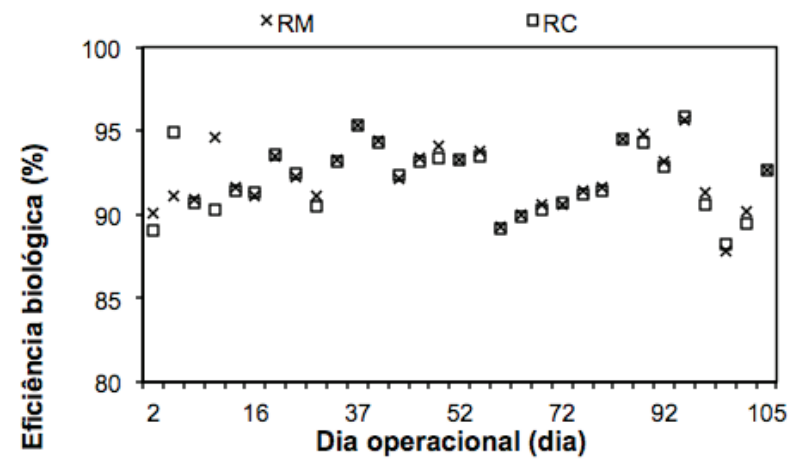

Figura 21 - Série temporal da eficiência biológica dos reatores RM e RC na Etapa 1.

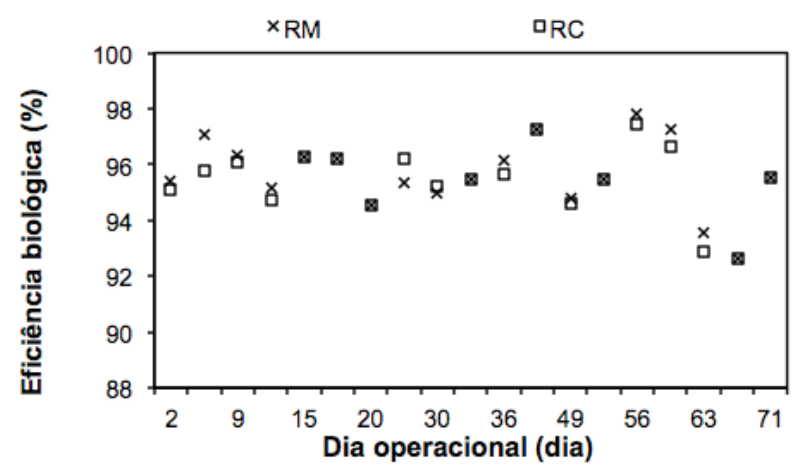

Figura 22 - Série temporal da eficiência biológica dos reatores RM e RC na Etapa2.

\section{CONVERSÃO A METANO}

Analisando a remoção de matéria orgânica pelo percentual de DQOremovida e convertida a metano (\%DQOremovida-CH4) (Figuras 23 e 24), na Etapa 1, verifica-se um comportamento similar entre os dois reatores, porém, de maneira sistemática, houve uma tendência do reator RM apresentar valores mais elevados. Na Etapa 2, as diferenças foram mais claramente observadas ao longo de todo o período operacional. Provavelmente a maior retenção de sólidos propiciou uma maior taxa de conversão em consequência do maior tempo de retenção de sólidos no reator RM (VAN HAANDEL, et al., 2015). Em termos medianos a conversão de DQO foi $20 \%$ superior no reator RM na Etapa 1 e 52\% na Etapa 2. Esses resultados confirmam a maior retenção de sólidos no reator RM, e podem explicar o fato de não terem sido observadas diferenças tão claras entre os dois reatores, na análise dos parâmetros SST, DQQ e na eficiência de retenção, em razão de que uma parte dos sólidos retidos no reator foi convertida a metano. $O$ que explica a maior conversão da matéria orgânica no reator $\mathrm{RM}$ em relação ao reator RC. Vale ressaltar que esses resultados revelam um bom potencial de aplicação desse reator, especialmente no cenário atual do aproveitamento energético do biogás.

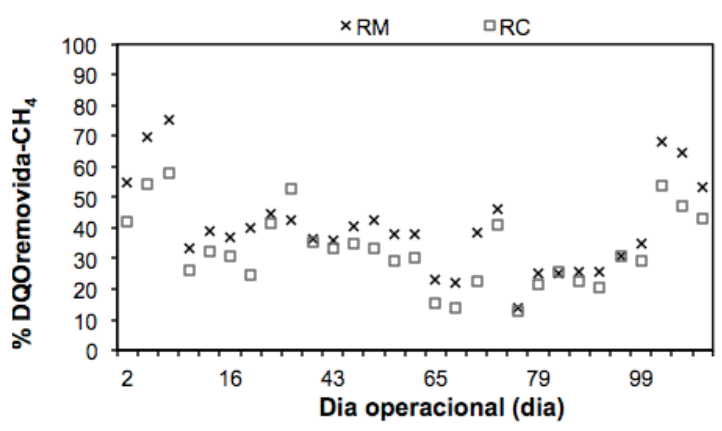

Figura 23 - Série temporal do percentual de DQQOremovida convertida a metano na Etapa 1. 


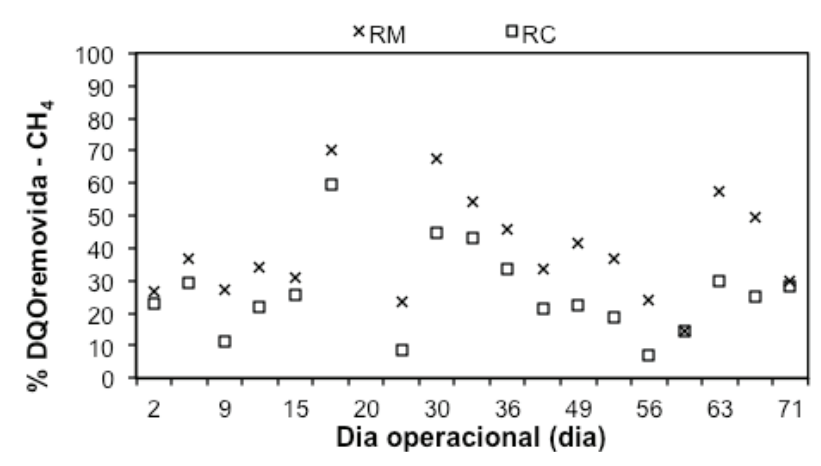

Figura 24 - Série temporal do percentual de DQQOremovida convertida a metano na Etapa 2.

\section{CONCLUSÕES}

Os resultados das concentrações efluentes de SST e SSV revelaram que o reator UASB modificado, mesmo tendo sido projetado com um compartimento de decantação em condições mais críticas, apresentou menores concentrações de sólidos no efluente, quando comparado ao reator UASB convencional, em ambas as etapas operacionais. Além disso, as análises comparativas diretas das concentrações de sólidos no efluente, e à luz do atendimento do padrão de lançamento de efluentes, permitiram concluir que o reator UASB modificado apresenta maior confiabilidade na produção de um efluente com menores teores de sólidos.

No que diz respeito à eficiência de retenção física de sólidos, também foi constatado que o reator UASB modificado apresentou melhor desempenho em relação à configuração convencional. Erroneamente, poderia-se pensar que o ganho de desempenho não tenha sido tão expressivo, uma vez que as diferenças percentuais podem não ter revelado isso de forma clara. Entretanto, os resultados de DQOtotal efluente e, especialmente, as maiores taxas de conversão da matéria orgânica a metano não deixam dúvidas de que o reator apresentou maior retenção física de sólidos, que em boa parte foram completamente digeridos.
Embora a redução das concentrações de sólidos no esgoto bruto possa ter interferido na avaliação do efeito da redução da velocidade na abertura de passagem, empregado da primeira para na segunda etapa operacional, é pouco provável que somente esse aspecto tenha proporcionado o melhor desempenho do reator UASB modificado. Especialmente quando se observa, novamente, conversão da matéria orgânica a metano.

Finalmente, conclui-se que os aperfeiçoamentos tecnológicos empregados no reator modificado comprovaram sua eficácia, e que essa tipologia de reator proposta tem potencial de aplicação prática. Essa conclusão é atribuída ao fato de que nessa inovadora configuração não foi prevista a introdução de novos elementos no reator, que possam elevar seus custos, além do fato que essa configuração tem potencial para, simultaneamente, garantir a maior retenção de sólidos, impedir o acúmulo de escuma no separador (uma vez que a mesma pode deixar o compartimento de gases) e aumentar a produção/recuperação de gases, conforme demonstrado. Ressalta-se que todos esses aspectos vêm sendo estudados e devidamente otimizados.

\section{REFERÊNCIAS}

AIYUK, S.; ODONKOR, P., THEKO, N., VAN HAANDEL, A. AND VERSTRAETE, W. Technical Problems Ensuing From UASB Reactor Application in Domestic Wastewater Treatment without Pre-Treatment. International Journal of Environmental Science and Development, Vol.1, No.5, December 2010.

ABNT - Associação Brasileira de Normas Técnicas. NBR 12209 Elaboração de projetos hidráulico-sanitários de estações de tratamento de esgotos sanitários, 2011.

AWWA/APHA/WEF. Standard Methods for the Examination of Water and Wastewater. 22. ed. Washington. 2012.

CAVALCANTI, P.F.F. Integrated Application of the UASB reactor and ponds for domestic sewage treatment in tropical conditions Ph.D. Thesis Wageningen University, The Netherlands, p. 141, 2003. 
CHERNICHARO C. A. L.; VAN LIER, J. B. NOYOLA, A.; RIBEIRO, T. B. Anaerobic sewage treatment: state of the art, constraints and challenges. Rev Environ Sci and Biotechnol., v.5: p. 3-19, 2015.

DE PAULA, F.S. Influência de Aspectos Hidráulicos na Otimização de Parâmetros de Projeto de Reatores UASB Tratando Esgotos Domésticos. Dissertação (Mestrado em Saneamento, Meio Ambiente e Recursos Hídricos). Escola de Engenharia da Universidade Federal de Minas Gerais, 123p, 2007.

ELMITWALLI, T., A., SKLYAR, V., ZEEMAN, G., LETTINGA, G. Low temperature pre-treatment of domestic sewage in anaerobic hybrid or an anaerobic filter reactor. Bioresource Technology, v. 82, p. 233-239, 2002.

GASPERI, R.L.P. Caracterização de resíduos de caixas de gordura e avaliação da flotação como alternativa de pré-tratamento. Dissertação (Mestrado em Hidráulica e Saneamento). Escola de Engenharia de São Carlos, 71p, 2012.

LEITÃO, R.C. Robustness of UASB reactors treating sewage under tropical conditions. Ph.D. Thesis. Wageningen University, The Netherlands, p. 160, 2004.
ROSA, A. P.; CHERNICHARO, C. A. L.; MELO, G. C. B. Contribuição para o aproveitamento energético do lodo de ETEs em processos térmicos. Revista DAE, Edição no: 198, No. 1578, p. 55-62, 2015.

SANTOS, S. L.; CHAVES, S. R.M.; VAN HAANDEL, A. Influence of phase separator design on the performance of UASB reactors treating municipal wastewater. Water SA Vol. 42 No. 2 April 2016.

VAN HAANDEL, A.; SANTOS, S. L.; CHAVES S. R. M. Influência do projeto do separador de fases sobre o desempenho do reator UASB no tratamento de águas residuárias municipais. Revista DAE, Edição no: 200, No. 1615, p. 64-75, 2015.

VAN HAANDEL, A.; LETTINGA, G. Tratamento anaeróbio de esgoto. Um manual para regiões e clima quente. Ed. Campina Grande, Brasil: Universidade Federal da Paraíba, 1994.

VON SPERLING, M. Princípio do tratamento biológico de águas residuárias - Introdução à qualidade das águas e ao tratamento de esgotos. Departamento de Engenharia Sanitária e Ambiental DESA/UFMG - 3. ed. Belo Horizonte, v.1, p.452., 2005. 